\title{
ECONOMIC VIABILITY OF UNDER FLOOR HEATING SYSTEM: A CASE STUDY IN BEIRUT CLIMATE
}

\author{
K. Ghali \\ Department of Mechanical Engineering, Beirut Arab University, Beirut, Lebanon
}

\begin{abstract}
This paper explores the economic feasibility of the underfloor heating system for the climatic conditions of Beirut. A case study of a typical residential room $\left(150 \mathrm{~m}^{2}\right)$ is selected to compare its heating energy requirement when using either the conventional convective heating system or the underfloor heating system at similar comfort and indoor air quality conditions. Two mathematical models are developed, a steady space thermal model to establish the energy consumption at the peak load and a transient simulation model to find the energy consumption during the winter heating season. In addition, the economic feasibility of the underfloor heating system is assesd when integrated with solar energy.

Based on the steady space model, the calculated peak heating load is reduced by $20 \%$ when the test space is heated by the underfloor heating system and a thermal comfort level of PPD $18.3 \%$ is achieved for a floor temperature of $27.4{ }^{\circ} \mathrm{C}$. The simulation results of the transient space model indicates that the seasonal heating energy consumption is reduced by $18 \%$ and that the yearly energy savings is $\$ 104$ for an on-off control strategy that maintains a PMV comfort level greater than -0.5 . The pay back period of the underfloor heating system is 10 years for an initial incremental cost of $\$ 850$. When integrated with 10 solar collector units, the yearly energy savings of the integrated system is increased to $\$ 350$ and the pay back period is 14 years.
\end{abstract}

Keywords: Underfloor, Thermal comfort, solar energy

\section{INTRODUCTION}

Heating for thermal comfort can be achieved by: 1) convective heating where the heating load is indirectly sastisfied by heating the space air; 2) by radiant heaters which directly satisfy the radiant heating loads by the proper sizing and installation of the radiant heaters and 3) by under floorheating where the surface of the heated concrete transfers the heat to the space by convection and radiation. The design of radiant and under floor heating systems is not as direct as the case of the conventional heating system. The design guidelines for sizing and calculating the energy consumption of a forced air heating system is well-established by Ashrae [1]. However, the design of radiant and under floor heating system have several added complexities that are not present in a conventional system. These difficulties, which include the thermal storage of the concrete slab and the combined radiative and convective heat transfer from the slab surface, makes underfloor heating system difficult to model and not as popular as the forced heating system.

In recent years, considerable attention has been given to radiant and underfloor heating systems as a method of heating warehouses, schools, and residential houses. Buckley [2] reported that radiant heating can reduce energy costs by $30 \%$ or more with equal comfort compared to convection heating. Strand et.al [3] developed a transient heat conduction model through the building walls to determine the radiant system efficiency and to compare the underfloor heating system to the conventional convective system and found that the radiant system is more energy efficient. Van Gerpen and Shapiro [4] focused on the thermal storage of the slabs and analyzed the use of buried heating elements at different depth to shift some electric power demand to off-peak hours. While Athienitis and Chen [5] developed control strategies to reduce operational cost of the radiant heating system and investigated the performance of an electric floor radiant heating system with thermal storage. Also, Athienitis [6] presented a non-linear finite difference numerical model to study the performance of a floor heating system with high solar gain.

In addition of having the potential to be an energyefficient alternative to the forced heating system, the underfloor heating is characterized by minimal indoor air circulation compared to the convective heating. The underfloor heating system relies on natutal air movement whereas the convective heating uses forced air circulation. The lower air velocity increases the human comfort and also reduces the conduction transmission through exposed partitions and external walls. Also the underfloor heating is characterized by having a uniform temperature profiles in heated spaces and homogenous temperature distribution. The radiant floor heating has been found to cause minimal floor-toceiling temperature gradients [7]. In underfloor heating the warmth starts at the feet where it is mostly desired instead of blowing hot air from air outlets located at the ceiling level which causes excess warmth at the head height which will result in discomfort. The temperaure of the air that satisfies thermal comfort in underfloor heating is generally lower than the air temperature of the conventional convective heating system. The thermal comfort at the lower air temperature is achieved because of the higher mean radiant temperature as was found by 
Ghali et.al. [8]. The ability to maintain low indoor air temperature reduces heat loss by transmission and by infiltration and could result in a better indoor air quality at low energy cost.

The underfloor heating system have gained popularity in Europe because of the potential they can provide in creating thermally comfortable environment and a better internal air quality at lower energy consumption. However such a heating system is unpopular in Lebanon. This makes it very tempting to study the economic viability of such a system in Beirut especially when knowing that one third of the energy (electricity) produced in Lebanon is spent on space heating of residences and commercial buildings. Lebanon, in the absence of rich natural resources has to depend on imported oil for its energy use. The continuing rise in energy demand, costs and the associated environmental pollution problems are causing increased emphasis on the investigation of potential energy efficient heating systems.

The main objective of this research is to explore the economic feasibility of the under floorheating system for the climatic conditions of Lebanon. A case study of a typical space in Beirut is considered. A comparison will be presented of the annual energy consumption and cost of the underfloor heating system as compared to that of the conventional heating system at similar comfort and indoor air quality conditions. In addition, the econmic performance of the underfloor heating system will be assesd when integrated with solar energy.

\section{Feasibility of the Under-Floor Heating System to a Test Case in Beirut}

The test case considered for the study is $(10 \mathrm{~m} \times 5 \mathrm{~m} \times 3 \mathrm{~m})$ space. The north wall has a single glazing window of area equal $7.5 \mathrm{~m}^{2}$ with an overall heat transfer coefficient, $\mathrm{U}_{\mathrm{g}}$, of $5.8 \mathrm{~W} / \mathrm{m}^{2} \mathrm{k}$. The ceiling and floor are considered internal partitions. The overall heat transfer coefficient of the insulated floor is $0.5 \mathrm{~W} / \mathrm{m}^{2} \mathrm{~K}$ while that of the ceiling is 2.5 $\mathrm{W} / \mathrm{m}^{2} \mathrm{~K}$. The vertical walls are external surfaces that are adjacent to the outside air with an assumed overall heat transfer coefficient of $U_{w}$ of $3 \mathrm{~W} / \mathrm{m}^{2} \mathrm{~K}$ which is typical for Lebanese buildings construction material.

The conventional forced convective heating system was simulated using TRNSYS thermal software [9] for $0.75 \mathrm{ACH}$ and indoor design condition of $23{ }^{\circ} \mathrm{C}$ and $50 \%$ relative humidity. The simulation was run from the month of (November-March) to determine the heating peak load Fig. 1 and also to determine the monthly energy requirement for heating Fig. 2.

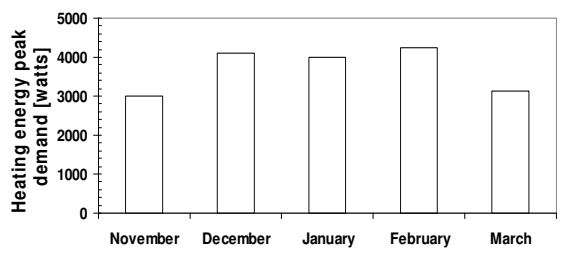

Fig.1: The monthly peak demand of the test case during the heating season for the conventional system

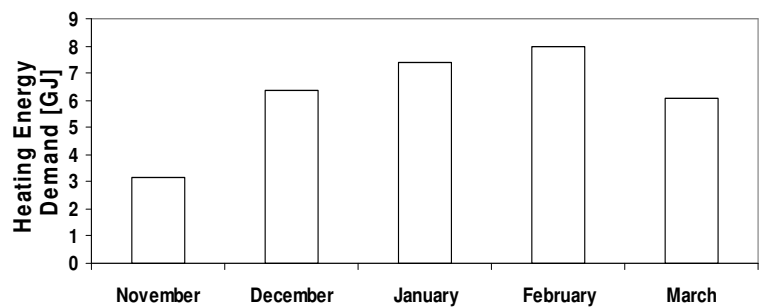

Fig.2: The monthly space energy demand during the heating season for the conventional system

The peak heat load is $4250 \mathrm{~W}$. It occurred on the $26^{\text {th }}$ of February. The calculated mean internal space surface temperature is $17.1{ }^{\circ} \mathrm{C}$ when the internal air temperature was controlled at $23{ }^{\circ} \mathrm{C}$. The resulted human thermal satisfaction with the thermal environment at the peak was also calculated by TRNSYS. The predicted mean vote (PMV) is -0.79 and the percentage of dissatisfied people (PPD) is $18.3 \%$.

To study the economic feasibility of the under floor heating system for the climatic conditions of Beirut, it is important to determine the energy requirement of this heating system at the peak winter season conditions for equal PPD comfort values obtained from the conventional heating system. This step is very important because it will determine the economic viability of such a system since the capital cost and installation of the underfloor heating system is more than that of the conventional forced air heating system. In the following, two mathematical models will be presented, a steady space thermal model to establish the energy consumption at the peak load and a transient simulation model to find the energy consumption during the winter heating season.

A. Steady Space Thermal Model: The energy requirement for heating the space at a specific thermal comfort level is achieved as follows: For a particular surface temperature of the floor the internal space surface temperatures and air temperature are computed by the steady space thermal model which will be explained in the next paragraph. The internal surface temperature values are then used to determine the mean radiant temperature, mrt. The resultant value of the mrt along with the internal air temperature are used in Fanger model [10] to determine the comfort level of a sedentary human subject. If the obtained PPD comfort level is not equal to the specific required value of comfort, then the floor temperature is changed. This process is continued until convergence occurs and the comfort level of PPD is equal to the required value. Once the comfort level is achieved the heat energy requirement can be calculated by the determination of the total heat loss from the space. The formulation of the steady space thermal model is adapted from Howell et.al [11] model that was developed for sizing radiant heater panels.

Each space surface ( 4 walls, ceiling and window) is in radiant exchange with all other surfaces and is in convective exchange with the air in the room. The sum of these two heat flows $\mathrm{q}_{\mathrm{r}}$ and $\mathrm{q}_{\mathrm{cv}}$, will under steady 
state conditions equal to the conductive heat flow through the surface:

$$
q_{r}+q_{c v}+q_{c d}=0
$$

where,

$\mathrm{q}_{\mathrm{r}}$ net radiation heat transfer from surface, $\mathrm{W} / \mathrm{m}^{2}$

$\mathrm{q}_{\mathrm{cv}}$ convective heat transfer, $\mathrm{W} / \mathrm{m}^{2}$

$\mathrm{q}_{\mathrm{cd}}$ conduction through the surface, $\mathrm{W} / \mathrm{m}^{2}$

The radiant exchange rate $\left(\mathrm{q}_{\mathrm{r}}\right)$ for each surface can be expressed as:

where,

$$
q_{r, i}=\varepsilon \sigma T_{i}^{4}-\sum_{j=1} \varepsilon_{i} \sigma T_{i}^{4} F_{A_{i}-A_{j}}
$$

$\mathrm{q}_{\mathrm{r}, \mathrm{i}}$ net radiant heat transferred from surface $\mathrm{A}_{\mathrm{i}}, \mathrm{W} / \mathrm{m}^{2}$

$\mathrm{T}_{\mathrm{i}}$ absolute temperature of surface $\mathrm{A}_{\mathrm{i}},{ }^{\circ} \mathrm{C}$

$\sigma$ Stefan-Boltzman constant, $5.67 \times 10^{-8} \mathrm{~W} / \mathrm{m}^{2} \mathrm{k}^{4}$

$\mathrm{F}_{\mathrm{Ai}-\mathrm{Aj}}$ angle factor from surface $\mathrm{i}$ to surface $\mathrm{j}$

$\varepsilon$ emissivity of the surface $A_{i}, 0.9$

The angle factors are calculated from algorithms available in Incropera and Dewitt [12] and the convective heat transfer is evaluated from the following equation:

$q_{c v, i}=h_{c, i}\left(T_{i}-T_{a}\right)$

where,

$\mathrm{q}_{\mathrm{cv}, \mathrm{i}}$ convective heat transfer from surface $\mathrm{i}, \mathrm{W} / \mathrm{m}^{2} \mathrm{~A}$

$\mathrm{h}_{\mathrm{c}, \mathrm{i}}$ convective heat transfer coefficient, $\mathrm{W} / \mathrm{m}^{2} \mathrm{~K}$

$\mathrm{T}_{\mathrm{a}}$ internal space air temperature, ${ }^{\circ} \mathrm{C}$

$\mathrm{T}_{\mathrm{i}}$ surface $\mathrm{A}_{\mathrm{i}}$ temperature, ${ }^{\circ} \mathrm{C}$

The convective heat transfer coefficients, $h_{c, i}$, is calculated from correlation from the book of Incropera and Dewitt [12] and the conductive heat transfer, $\mathrm{q}_{\mathrm{cd}}$, per unit area, $A_{i}$, is given by:

$q_{c d, i}=C_{i}\left(T_{i}-T_{o}\right)$

where,

$\mathrm{C}_{\mathrm{i}}$ overall wall conductance from inside surface to the outside ambient air depending on the wall construction material, $\mathrm{W} / \mathrm{m}^{2} \mathrm{~K}$

$\mathrm{T}_{\mathrm{o}}$ ambient air temperature, ${ }^{\circ} \mathrm{C}$

The above analysis results in six coupled non-linear equations because of the radiation term with seven unknown variables( six unknown surface temperatures and one temperature for the space air). Therefore, an additional energy balance equation on the air within the space will be needed to solve for the unknown temperatures. The results of the steady state space is used to determine the peak heat load of the system by summing up the heat losses from each surface and the infiltration load.

B.Transient Space thermal Model: The evaluation of the under floor heating requires a detailed transient simulation analysis of the system. The transient simulation gives an estimation of the energy consumption of the designed unferfloor heating system over a period of time to compare its performance with the conventional heating system.

In the transient analysis, the ambient conditions are not constant and are obtained from measured weather data files for a typical day of each month for which heating is needed (November to March), Ghaddar et.al. [13]. The thermal storage of the wall cannot be ignored and the floor temperature cannot be considered constant during the simulation period. Therefore, the equations of the steady space model have to be modified to include these effects. The space wall is assumed to be composed of one concrete $25 \mathrm{~cm}$ layer thickness and the heat transfer across wall is one dimensional and it is represented as follows:

$\frac{\partial}{\partial x}\left(k_{i} \frac{\partial T_{w i}}{\partial x}\right)=\frac{\partial\left(\rho_{i} c_{i} T_{w i}\right)}{\partial t}$

Where,

$K_{\mathrm{i}}$ conductivity of each layer of wall, $\mathrm{W} / \mathrm{m}{ }^{\circ} \mathrm{C}$

$\mathrm{C}_{\mathrm{i}}$ is the thermal capacitance of each layer, $\mathrm{kJ} / \mathrm{kg}{ }^{\circ} \mathrm{C}$

$\rho_{\mathrm{i}}$ is the density of each layer, $\mathrm{Kg} / \mathrm{m}^{3}$

The outer boundary of each wall exchanges heat with outside environment by convection and the inner surface exchanges heat with the inside space by convection and radiation.

Since the floor is considered a partition (i.e it is adjacent to an air conditioned space), a lumped temperature for the floor is assumed. The heat equilibrium for the floor can be written as:

$U_{w t} A_{w t}\left(T_{w a}-T_{f}\right)-q_{r}-q_{c v}=m_{f} c_{f} \frac{d T_{f}}{d t}$

Where,

$\mathrm{U}_{\mathrm{wt}}$ overall heat transfer coefficient between flowing water and concrete, $\mathrm{W} / \mathrm{m}^{2} \mathrm{~K}$

$\mathrm{A}_{\mathrm{wt}}$ surface area of the embedded piping system in contact with the concrete, $\mathrm{m}^{2}$

$\mathrm{T}_{\text {wa }}$ average circulating water temperature, ${ }^{\circ} \mathrm{C}$

$\mathrm{T}_{\mathrm{f}}$ average floor temperature, ${ }^{\circ} \mathrm{C}$

$\mathrm{m}_{\mathrm{f}} \quad$ mass of the floor, $\mathrm{Kg}$

$\mathrm{c}_{\mathrm{f}}$ heat capacitance of the floor, $\mathrm{kJ} / \mathrm{kg}{ }^{\circ} \mathrm{C}$

The simulation for the transient model is performed for an on-off control strategy which is used to maintain a level of thermal comfort greater than a PMV of -0.5 . Whenever, the estimated PMV is lower than -0.5 , the circulating water is turned on to transfer heat to the concrete floor. The implicit Cranck-Nicolson method is used in the wall temperature equations and the sensitivity of the results to the time step and the grid size of the wall was examined. A spatial grid size of 1.5 $\mathrm{mm}$ for the external walls and a time step of $100 \mathrm{~s}$ are used. For each month of the heating season, the 
simulations are done over a period of 10 days to reach a convergent steady periodic solution for a period of 24 hours. The periodic solution is obtained for a typical day of every month of the heating season. The average heating energy requirement of each month is estimated from the typical day energy consumption.

\section{Results and Discussions}

A. Steady space thermal model results: Based on the steady space model, the temperature of the floor that achieves thermal comfort level PPD of $18.3 \%$, which is equal to the value obtained by the air forced conventional system, is equal to $27.4^{\circ} \mathrm{C}$. The calculated peak heating load is 3371 Watts which is a reduction of $20 \%$ of the peak load obtained by the conventional system for the same level of comfort. The mean radiant temperature of the underfloor heating system at the peak load is $22.5^{\circ} \mathrm{C}$ and the air temperature is $20^{\circ} \mathrm{C}$. The thermal comfort level of PPD $18.3 \%$ is attained at a lower temperature compared to that of the forced convective system because of the higher mean radiant temperature. The reduction of the heating load originates from the reduction of the infiltration air load. However, the cost effectiveness cannot be assessed on the basis of the peak load but on the energy consumption of the system for the entire heating season.

B. Transient space thermal model results: The underfloor heating piping system that is used in the simulation of the transient model has a diameter of 20 $\mathrm{mm}$ with a thickness of $2 \mathrm{~mm}$ and a pipe thermal conductivity of $0.38 \mathrm{~W} / \mathrm{m}^{2} \mathrm{~K}$. It is located $50 \mathrm{~mm}$ below the surface floor concrete layer at a spacing distance of $300 \mathrm{~mm}$. The simulation of the transient model requires the knowledge of the average temperature of the heating water, $\mathrm{T}_{\mathrm{wa}}$, and the overall heat transfer coefficient between the flowing water and concrete, $\mathrm{U}_{\mathrm{wt}}$. The average temperature of the heating water can be calculated from the peak load using the steady state model. $U_{w t}$ is related to the internal resistance of the flowing water and the conductive resistance of the piping system.

The circulating water flow rate in the underfloor heating system, $\mathrm{m}_{\mathrm{wt}}$, required in determining the internal resistance of flowing water is calculated from the steady space thermal model for a heating water temperature difference of $5^{\circ} \mathrm{C}$ by the following equation:

$$
m_{w t}=\frac{Q_{h}}{c_{w t}(5)}
$$

Where,

$\mathrm{Q}_{\mathrm{h}}$ peak heat load, W

$\mathrm{c}_{\mathrm{wt}}$ specific heat of water, $\mathrm{kJ} / \mathrm{kg}{ }^{\circ} \mathrm{C}$

The simulation results of the transient space model indicates the monthly heating energy load of the underfloor heating system for the test case as shown in Fig. 3.

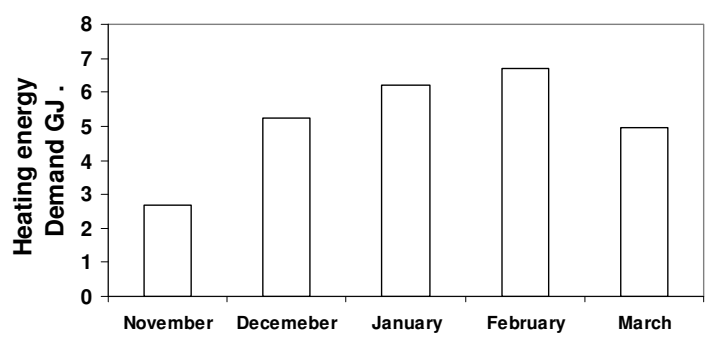

Fig.3: The monthly energy demand of the test case using the under floor heating system

The maximum heating energy demand occurs in the month of February. A reduction in total energy demand of $18 \%$ energy is attained when underfloor heating replaces the conventional heating system while satisfying comparable comfort levels. The reduction in energy consumption is only indicative since it is limited to the test case and to the chosen control strategy. A different control strategy could have been used in the simulation which might result in a better energy reduction.

It is important to perform an economic feasibility analysis on the test case because the underfloor heating system has a higher initial cost. This is due to the cost and installment of the water piping system. The incremental initial cost of the underfloor heating system is considered for a value of $\$ 850$ over the initial cost of the conventional system. The cost of other equipment is assumed to be the same for both systems such as the boiler. On the other hand, the yearly heating energy consumption is reduced from from $34 \mathrm{GJ}$ to $27.8 \mathrm{GJ}$ for the underfloor heating system compared to the conventional heating system. The oil energy bill is assumed to be $0.5638 \$ / \mathrm{kg}$. The saving in the yearly energy bill is about $104 \$$. Assuming a discount rate of 0.08 and an inflation rate of 0.05 . Figure 4 shows the pay back period of the underfloor heating system is about 10 years.

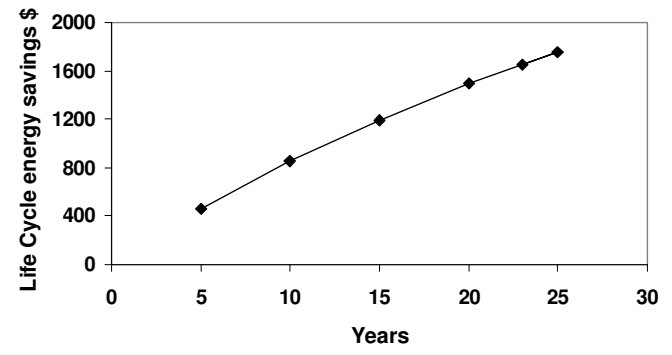

Fig. 4 Life cycle savings of the underfloor heating system

C. Undefloor heating integrated with solar energy feasibility results: Underfloor heating has the potential to be an energy-efficient alternative to the conventional system when tied with solar energy Since moderate water temperatures is used in its heating system. The economic feasibility of integrating the under floor with solar energy is investigated for the Beirut test case. The solar system is composed of 10 single glazing flat-plate 
collectors that stores solar energy in a water storage tank. Each unit has an effective area of $2.872 \mathrm{~m}^{2}$. The transient performance of the collector-tank system is simulated numerically using the theory of Hottel and Whillier presented by Duffie and Beckman [14] during the winter heating season. If the water temperature in the storage tank collector system is higher than the water temperature leaving the underfloor heating, then the circulating heating water is assumed to pass through the storage tank, if not; water is bypassed directly into the auxiliary heater as shown in Fig. 5. The water pump of the solar collector turns whenever the temperature difference between the tank and the absorber plate exceeds $10^{\circ} \mathrm{C}$ and shuts off when this difference drops below $0.5^{\circ} \mathrm{C}$. The simulation of the solar collector tank system is performed by using the first order EulerForward integration scheme. A quasi-steady-state system is assumed; i.e. the variables, while varying from hour to hour, are considered constant during every hour of the analysis. The ambient conditions are obtained from the measured weather files, Ghaddar [13].

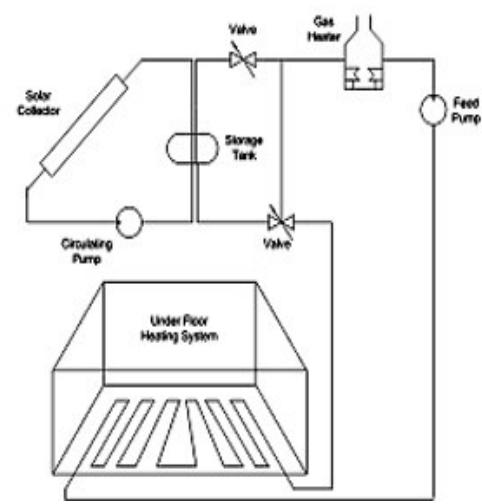

Fig. 5 Integrated solar underfloor heating system

The simulation is performed for a typical day of every month of the heating season to obtain energy contribution of the solar collector tank system. The integrated solar underfloor heating system energy requirement for the heating season is reduced to $15.5 \mathrm{GJ}$ and the yearly energy savings is increased to $\$ 350$. An economic assessment is performed for a collector-tank initial cost of $\$ 100 / \mathrm{m}^{2}$. The pay back period for the integrated system is 14 years.

\section{Conclusions}

A transient and steady thermal space models are developed to investigate the economic feasibility of underfloor heating system to a test case in Beirut in comparison with the conventional heating system. The comparison between the two systems is performed under equal comfort levels and indoor air quality. The underfloor heating system reduces the seasonal heating energy consumption by $18 \%$ and results in yearly savings of $\$ 104$. The pay back period of the underfloor heating system is 10 years. The integrated solar under floor heating system increases the energy savings to
$350 \$$ and the pay back period of the integrated system is 14 years for a collector-tank initial cost of $\$ 100 / \mathrm{m}^{2}$

\section{References}

1- Ashrae Handbook, 1993. Fundamentals, Published by the American Society of Heating, Refrigerating and Air-Conditioning Engineers, Inc.

2- N.A. Buckley, "Application of radiant heating saves energy", Ashrae Transactions 96(2), 1989.

3- R.K.Strand and C.O. Pedersen, "Analytical verfication of heat source transfer functions", First Joint Conference of International Simulation Societies, Zurich, Switzerland, 1994

4- J.H Van Gerpen, 1980,"The design and analysis of slab heating systems. M.Sc. Thesis, Iowa State University, Ames, Iowa.

5- A. K. Athienitis T.Y. Chen, "Experimental and theoretical investigation of floor heating with thermal storage", Ashrae Transactions 99(1), 1993.

6- A. K. Athienitis, "Numerical model of floor heating system", Ashrae Transactions 99(1), 1994.

7- E. R. Ambrose, "Progress report on off-peak electric heating", Air conditioning Heating and Ventilating, Vol (58), July, pp. 51-56, 1961.

8- K. Ghali, S. Chehade, and K. El-Khoury, "Radiant floor heating: an opportunity for energy savings", International conference on thermal Engineering: theory and applications, Beirut, Lebanon, 2004

9- TRNSYS, "A transient simulation program, version 15", Solar Energy Laboratory, University of Wisconsin-Madison, USA, 2004.

10- Fanger, P.O. 1982. Thermal comfort. Robert E. Publishing Co., Malabar, Fl, USA.

11- R. Howell and S. Suryanarayana, "Sizing of radiant heating systems: part 1-ceiling Panels", Ashrae Transactions, vol. 96, part 1. pp 652664, 1990

12- F.P. Incropera and D.P. Dewitt, 1985. Fundamentals of heat and mass transfer, second edition. John Wiley and Sons. New York.

13- N. Ghaddar and A. Bsat, "Energy conservation of residential buildings in Beirut", International Journal of energy Research. 32 (2) 523-546, 1998.

14- J. A. Duffie and W. A. Beckman, 1980. Solar Engineering thermal processes. John Wiley and Sons. 